\title{
João Batista Libanio: os principais eixos temáticos de uma teologia em constante movimento
}

\author{
João Batista Libanio: the principal thematic \\ axes of a theology in constant movement
}

Geraldo De Mori, SJ

\section{Resumo}

João Batista Libanio, um dos maiores teólogos católicos brasileiros dos últimos 50 anos, falecido em 30 de janeiro de 2014, deixou uma contribuição ímpar para a teologia latino-americana. O jesuíta, de Belo Horizonte, elaborou seu pensamento em contato com a experiência eclesial da igreja do Brasil e da América Latina no pós-concílio, tendo também como interlocutores outros intelectuais, grupos e movimentos importantes dos diversos âmbitos do saber importantes para a inteligência da fé. $\mathrm{O}$ texto presente, elaborado a partir do colóquio realizado na PUC Rio em setembro de 2014, é um intento de sistematização da globalidade dos temas abordados pelo teólogo mineiro. Após uma apresentação dos principais traços do "modo libaniano de fazer teologia", o texto apresenta os principais eixos temáticos trabalhados por Libanio, privilegiando, sobretudo, seus escritos em forma de livro ou capítulos de livros.

Palavras-chave: João Batista Libanio, teologia da libertação, igreja latino-americana, teologia fundamental.

\begin{abstract}
João Batista Libanio, one of the most important Brazilian Catholic theologians of the last 50 years, who died on the $30^{\text {th }}$ of January, 2014, made a unique contribution to Latin American theology. The Jesuit, from Belo
\end{abstract}


Horizonte, developed his thought in contact with the ecclesial experience of the Church of Brazil and of Latin America in the post-conciliar period, as well as in dialogue with other intellectuals, groups and influential movements of various branches of knowledge important for the understanding of the faith. The present article, elaborated on the basis of the colloquium that took place at PUC Rio in September, 2014, is intended to systematize the major themes expounded by the theologian of Minas Gerais. After a presentation of the principal characteristics of the 'libanian theological method', the text details the principal thematic axes traversed by Libanio, privileging above all among his writings his books and chapters of books.

Keywords: João Batista Libanio, liberation theology, the Church of Latin America, fundamental theology.

\section{Introdução}

Por ocasião de seus 80 anos, em 2012, dentre as homenagens prestadas a Libanio, destaca-se a obra Teologia para viver com sentido ${ }^{l}$, que recolhia textos de autores que escreveram sobre alguns dos eixos norteadores de sua reflexão: a teologia fundamental, as comunidades eclesiais de base, a teologia da libertação. O livro também oferecia em apêndice uma bibliografia primária do teólogo mineiro ${ }^{2}$. Na entrevista dada a Flávio Senra em 2011, no programa Religare, transcrita na mesma obra, o próprio Libanio recorda a dificuldade de "perceber os eixos fundamentais que comandam seus escritos"3. Se se leva em conta o que isso representa em termos quantitativos e a diversidade de temas abordados por ele, perceber-se-á a dificuldade da tarefa a que se propõe esse texto. A bibliografia primária do autor tornou, porém, a tarefa menos difícil, possibilitando uma percepção de conjunto dos horizontes temáticos explorados por ele. Graças a isso, com Pedro Ribeiro de Oliveira, um texto escrito para o livro do $27^{\circ}$ congresso da SOTER já indicou alguns desses temas, que encontram, porém, nesse texto um desenvolvimento mais amplo ${ }^{4}$. Para a reali-

\footnotetext{
${ }^{1}$ MURAD, A.; BOMBONATO, V. Teologia para viver com sentido. São Paulo: Paulinas, 2012. ${ }^{2}$ DE MORI, G. Anexo II. Ouvinte e servidor da Palavra: Bibliografia primária de João Batista Libanio. In Teologia para viver com sentido, p. 211-238.

${ }^{3}$ SENRA, F. Anexo I. Entrevista a Flávio Senra. In Teologia para viver com sentido, p. 197-210. ${ }^{4}$ DE MORI, G.; OLIVEIRA, P. R. João Batista Libanio, SJ. In PANASIEWICZ, R.; VITÓRIO, J. Espiritualidades e dinâmicas sociais. Memória - Prospectivas. São Paulo: Paulinas, 2014, p. 186-200.
} 
zação da tarefa presente, foram importantes ainda os dados da bibliografia completa de Libanio, em elaboração na FAJE com a ajuda das bibliotecárias da Biblioteca Padre Vaz e de um aluno de iniciação científica ${ }^{5}$.

Esse texto propõe uma dupla entrada no pensamento teológico de Libanio: a primeira, dedicada ao que ele mesmo considera como sendo os elementos mais importantes de seu modo de fazer teologia, e a segunda, dedicada aos principais eixos temáticos de sua reflexão. Isso é feito com a conviç̧ão de que não se pode dissociar a forma do conteúdo, ou seja, só se pode sistematizar os conteúdos temáticos do pensamento de Libanio vendo como ele entende a teologia.

\section{O modo libaniano de fazer teologia}

Todos os que conheceram Libanio se recordam de sua capacidade de leitura e de síntese, de sua agilidade intelectual, de sua facilidade de relacionar as várias leituras do real feitas por campos distintos do saber. Ele se pronunciou várias vezes sobre seu jeito de fazer teologia, marcado, segundo ele, por algumas atitudes intelectuais e por determinados aspectos didáticos. A isso se devem acrescentar os "públicos" ou "lugares" a partir dos quais ele teologizava.

\subsection{Atitudes intelectuais}

Numa conferência feita à comissão teológica dos jesuítas da América Latina, em 2006, Libanio apresentou sete atitudes que marcam seu perfil intelectual ${ }^{6}$. Elas serão retomadas brevemente a seguir, com algumas explicações que ele mesmo dá de como as entende.

A primeira atitude é a "atenção crítico-dialética aos pressupostos ideológicos e antropológicos das afirmações". Trata-se, segundo o autor, de uma "perspicácia crítica, casada com a suspeita", que o levava a "desocultar a ideologia que se infiltra nas afirmações próprias e alheias" ". No fundo, mesmo

\footnotetext{
${ }^{5}$ As bibliotecárias Zita Mendes e Vanda Abreu Bettio acompanharam o estudante de teologia Mariano Torres Vargas, portador de uma bolsa de iniciação científica da FAPEMIG num projeto de iniciação científica, sob orientação de Geraldo De Mori. Esse trabalho será disponibilizado no Memorial João Batista Libanio, a ser criado em 2015.

${ }^{6}$ LIBANIO, J. B. Itinerário intelectual. Conferência apresentada em 2006 à comissão de teólogos da Conferência de Provinciais da América Latina - CPAL (pro manuscrito). Ver também LIBANIO, J. B. 70 anos de um teólogo. Entrevista de João Batista Libanio. Jornal de Opinião, Junho de 2002.

${ }^{7}$ Idem, p. 1.
} 
consciente de pertencer a várias instituições (a Igreja, a Companhia de Jesus, a faculdade de teologia), o teólogo mineiro buscava certa distância corporativa, sem perder, porém, a vinculação. De fato, quem não se impressionava com a agudeza crítica de suas análises sobre a Igreja, por exemplo, sem, ao mesmo tempo, nunca perder o sentido de pertença, que lhe era tão visceral.

A segunda atitude, que lhe foi atribuída, segundo ele, por Leonardo Boff, é a da "ars combinatoria", ou seja, a capacidade de fazer uma teologia ao mesmo tempo contextual, pois

caminha pela Igreja universal, Igreja local, comunidades eclesiais de base, movimentos sociais, vida religiosa, inteligência acadêmica com inquietações de transformação da sociedade; aberta à escuta do povo, das interpelações dos pensadores com quem dialoga, evitando dialeto hermético do especialista num único autor ou tema; atenta às urgências do homem da rua como diakonia da palavra oral e escrita. ${ }^{8}$

Isso se expressa na facilidade que Libanio tinha em conjugar análises com sínteses, tornando-o "um teólogo generalista", ou seja, não tão preocupado com os detalhes do especialista, mas afeito à transversalidade, ou seja, à articulação de saberes plurais, aproveitando as várias leituras feitas, transferindo métodos e categorias de outros tipos de conhecimento para a teologia, a espiritualidade e a pastoral.

A terceira atitude ele a denomina de "caminho linguístico". Segundo o teólogo jesuíta, seu método teológico era regido pelo axioma: "cada afirmação é resposta; resposta supõe pergunta; para entender a afirmação (resposta) deve-se saber a que pergunta responde" 9 . Tanto em seus escritos quanto em suas conferências, ele sempre começava apresentando com clareza a pergunta que pretendia responder, para que os leitores e ouvintes tivessem condições de contrapor a resposta a que daria à pergunta inicialmente feita. A mesma maneira de proceder era aplicada nas monografias, dissertações e teses orientadas pelo teólogo jesuíta. Em suas leituras também se deixava guiar por perguntas: "que diz o texto, que ele me diz e que ele me faz dizer para os outros?"10. O mais importante, observava Libanio, era a última questão, ou seja, o que a leitura que fiz me faz dizer de novo? Mais que a informação, que

\footnotetext{
${ }^{8}$ Idem, p. 2.

${ }^{9}$ Idem, p. 3.

${ }^{10}$ Idem.
} 
"entulha a inteligência, gera fragmentação e esnoba erudição", importa buscar transmitir o universo profundo da categoria ${ }^{11}$.

A quarta atitude ele a denomina de "estruturas gerais do pensar". Ela está na origem dos esquemas, modelos, aproximações, cenários e linguagens propostos por Libanio para abordar o objeto de seu estudo. O teólogo mineiro começou utilizando a categoria "esquemas mentais", quando escreveu as obras sobre a formação da consciência crítica (objeto, sujeito e dialético-social) ${ }^{12}$. Daí passou à categoria dos "modelos" culturais (tradicional, moderno subjetivo, moderno social, pós-moderno); de Igreja (como sociedade, como sacramento, como missão); da vida religiosa (tridentino, Vaticano II e Medellín-Puebla); da teologia (calcedônico, antropológico, sacramental, agápico, pascal). Para evitar a rigidez do termo modelo, Libanio passou a utilizar o termo "aproximação" em suas análises sobre a pastoral (aproximação religioso-moral, psicossocial e dialético-estrutural). Nos últimos anos, trabalhou mais com a metáfora do "cenário", utilizada para analisar a conjuntura eclesial (Igreja da instituição, Igreja carismática, Igreja da pregação e Igreja da práxis libertadora ${ }^{13}$. Nas obras sobre Jesus, um de seus últimos projetos editoriais, iniciado em 2011, recorreu ao termo "linguagens" 14 . Em todas essas estruturas gerais do pensar, diz ele, "preside a mesma atitude intelectual: encontrar estruturas que ajudem a sistematizar, ordenar, tornar inteligíveis elementos intelectuais, existenciais e práticos que circulam soltos no mundo sociocultural"15.

A quinta atitude, a da criticidade e responsabilidade, combina, segundo o teólogo jesuíta, a "criticidade teórica rigorosa" e o "impacto que ela produz na prática do fiel simples, na vida eclesial"16. Trata-se, nota Libanio, de combinar "um pensamento crítico em relação às ideias, mas respeitoso das pessoas, avesso

${ }^{11}$ Ibidem.

${ }^{12}$ LIBANIO, J. B. Formação da consciência crítica: subsídios filosófico-culturais. Petrópolis: Vozes, 1978. v. 1; IDEM. Formação da consciência crítica: subsídios sócio-analíticos. Petrópolis: Vozes, 1979. v. 2; IDEM. Formação da consciência crítica: subsídios psicopedagógicos. Petrópolis: Vozes, 1979. v. 3.

${ }^{13}$ Ver: LIBANIO, J. B. Cenários da Igreja: num mundo plural e fragmentado. São Paulo: Loyola, 1999. ${ }^{14}$ Ver: LIBANIO, J. B.; CUNHA, C. Linguagens sobre Jesus (1): as linguagens tradicional, neotradicional pós-moderna, carismática, espírita e neopentecostal. São Paulo: Paulus, 2011; LIBANIO, J. B. Linguagens sobre Jesus (2): as linguagens narrativa e exegética moderna. São Paulo: Paulus, 2012; IDEM. Linguagens sobre Jesus (3): as linguagens narrativa e exegética moderna. São Paulo: Paulus, 2012; LIBANIO, J. B.; GUIMARÃES, E. Linguagens sobre Jesus (4): as linguagens das juventudes e da libertação. São Paulo: Paulus, 2013.

${ }^{15}$ Itinerário, p. 4.

${ }^{16}$ Idem. 
às polêmicas e protestos"17. Quem o conheceu lembra-se de como era exímio nesta arte, utilizando-se de seu humor e de certa aparência de ingenuidade, que o fazia dizer criticamente o que pensava, sem, no entanto, ferir ou agredir as pessoas.

A sexta atitude é a do discernimento. Ela foi adquirida com a espiritualidade e o carisma inacianos, que ensinam a "captar o universal, o importante, o decisivo [a vontade de Deus] na fragilidade das mediações, das moções, dos sinais visíveis e localizados"18. Essa atitude, diz o teólogo mineiro, "é fundamental para a teologia na América Latina, que construiu sua reflexão a partir do pobre, da situação de opressão. A dialética entre o local e o universal da teologia reflete a estrutura do discernimento"19.

A sétima atitude é a que fez com que Libanio passasse de uma visão de mundo marcada pela atenção à essência, a uma atitude atenta à relação e à articulação. Segundo o teólogo jesuíta, ela é determinada pela "insatisfação com o já possuído" e a "insistente procura de novas compreensões da realidade". Ela "inclui também tratar os temas da teologia sob a perspectiva simultaneamente sistemática, pastoral e espiritual" e leva a ocupar-se com o destinatário. Interessa-me mais, diz o teólogo mineiro, "o que é importante para ele do que o que tenho a dizer. Isso modificava a postura básica nas aulas, palestras e homilias"20.

\subsection{Aspectos didáticos}

As atitudes acima elencadas estão associadas a aspectos didáticos que Libanio considerava fundamentais. No texto de 2006, cujo conteúdo se encontra também na entrevista dada a Flávio Senra em 2011, ele aponta quais desses aspectos lhe pareciam mais importantes.

O primeiro era a clareza. Para que um pensamento seja claro, observa o teólogo mineiro, é necessário que a pergunta que se quer responder também seja clara. Para verificar isso ele sugere que sejam utilizados critérios de exclusão e de inclusão. É preciso, por um lado, dissecar o problema que se quer estudar, escolher o que se vai abordar (inclusão) e, por outro, o que não vai ser objeto de estudo ou de reflexão (exclusão). A concretização disso se dá em um esquema em forma de perguntas e respostas, de tal modo que a cada resposta se abre à pergunta seguinte até que se terminem as perguntas.

\footnotetext{
${ }^{17}$ Ibidem.

${ }^{18}$ Ibidem, p. 5.

${ }^{19}$ Idem.

${ }^{20}$ Ibidem.
} 
O segundo aspecto é o caráter lógico do que se quer apresentar (conferência, comunicação) ou escrever (artigo, livro, capítulo de livro). Segundo Libanio, a lógica aparece no nexo que existe entre as perguntas. A arte de fazer esquemas desenvolve a capacidade lógica.

O terceiro elemento tem a ver com a produção de textos. $\mathrm{O}$ segredo, diz o teólogo jesuíta, é o esquema prévio, que "deve ser o mais detalhado possível"21. Não se pode poupar tempo e capricho em sua confecção. No caso de Libanio, a arte de escrever estava ligada às muitas conferências, minicursos e cursos que dava. De seus esquemas resultaram seus artigos e livros.

O último elemento importante apontado por Libanio é o da disciplina. É conhecido seu adágio: "o que não está no horário não existe”. Para o teólogo jesuíta, a disciplina dependia de decisões e podia ser aprendida. Escrever implica, por isso, austeridade afetiva, psíquica e física.

\subsection{Os vários "públicos” com os quais Libanio dialogou}

Para entender os diferentes eixos temáticos explorados por Libanio, é necessário descobrir quais eram os "públicos" ou interlocutores que se perfilavam por detrás das inúmeras perguntas às quais sua teologia buscou entender, responder e sistematizar. David Tracy, em sua obra $A$ imaginação analógica ${ }^{22}$, diz que toda teologia é o resultado de um diálogo com os três públicos do teólogo: a sociedade, a academia e a Igreja. Desse diálogo emergem respectivamente as três áreas ou disciplinas teológicas: a teologia prática, a teologia fundamental e a teologia sistemática. Essa nomenclatura e esse modelo heurístico não são certamente os de Libanio, mas é inegável que sua teologia se fez em contínuo diálogo com vários tipos de "públicos”, uns mais eclesiais, outros mais acadêmicos, outros mais sociais. A seguir serão elencados alguns desses grupos sem os quais não se pode entender sua reflexão e sua contribuição à inteligência da fé.

Um dos primeiros interlocutores com os quais iniciou o exercício de sua reflexão teológica foi o grupo de jovens Tropa, ao qual ajudou a constituir quando regressou ao Brasil após seus estudos na Europa e com o qual se reuniu durante toda a vida, acompanhando seu ingresso na vida adulta, acolhendo seus filhos e netos, com as novas interrogações que isso implicava.

${ }^{21}$ Idem, p. 7.

${ }^{22}$ TRACY, D. A imaginação analógica. A teologia cristã e a cultura do pluralismo. São Leopoldo: Unisinos, 2006. 
Boa parte desse grupo era composta de profissionais liberais de classe média, procedentes de várias áreas do saber. Seus membros traziam ao teólogo jesuíta as questões existenciais próprias à geração e ao meio social de uma intelectualidade católica típica do final dos anos 1960, e a evolução que ela sofreu nas décadas seguintes, tendo sido interlocutores constantes. O teólogo mineiro não era guru desse grupo, mas irmão, confidente, pai espiritual, que escutava $\mathrm{e}$ animava, não se escandalizando com o que ouvia, mas deixando-se interpelar, aprendendo deles as diferentes rupturas das certezas que traziam no final dos anos 1960 e que continuaram se instaurando nas décadas seguintes, buscando em tudo as frestas que se abriam ao sentido. No fundo, ele foi testemunha da passagem dos membros desse grupo de um modo de pensar tradicional, para o moderno e o pós-moderno.

Outro interlocutor central na vida teológica de Libanio foi o grupo Emaús, constituído de teólogos/as e intelectuais afinados/as com a igreja e a teologia da libertação. Esse grupo se reúne há quarenta anos, geralmente em Correas, perto de Petrópolis, RJ, e é um dos fóruns privilegiados onde foram gestadas as principais intuições e elaborações da teologia cristã e católica em nosso país sob o impulso inspirador das principais ideias do Concílio Vaticano II. O teólogo mineiro foi um dos membros mais fiéis desse grupo, constituindo uma de suas maiores referências. Segundo alguns de seus membros, era ele que coordenava os trabalhos, fazendo circular a palavra, tomando nota das ideias, sintetizando-as e, como gostava e sabia fazer, sistematizando-as ao redor de pistas que alimentavam o pensamento que aí era gestado. Esse grupo e o que nele era discutido antecipava em muitos casos os textos que alguns de seus membros escreveriam para iluminar a caminhada de fé das comunidades e pastorais no Brasil.

Um terceiro grupo que marcou o pensamento teológico de Libanio foi o dos alunos/as e professores/as da FAJE, onde foi docente por mais de trinta anos. Enquanto professor, não atuava apenas como catedrático, que detinha todo o saber a ser transmitido para um interlocutor meramente passivo ou ignorante. De propósito suas aulas nunca se reduziam a mero resumo do que já escrevera nem tampouco a uma exposição exaustiva de todo o conteúdo a ser transmitido. Trabalhava com esquemas, que despertavam no/a aluno/a o desejo de ir além e buscar mais. O esquema tutorial, que implantou no período em que foi diretor da faculdade, privilegiava o acompanhamento personalizado, que se mantém ainda hoje na FAJE. Nas monografias, dissertações e teses que orientou, criou um método próprio de pesquisa, que partia do tema 
a ser estudado, com suas questões e hipóteses de possíveis respostas, com o caminho para encontrá-las, e a bibliografia prévia. Na execução da pesquisa, ajudava o/a aluno/a a elaborar esquemas, primeiro genéricos, e depois detalhados, que facilitavam na redação final do texto escrito.

Foi um grande incentivador das vocações à teologia, escrevendo alguns de seus livros com discentes, com os quais estabelecia uma verdadeira parceria e amizade intelectual ${ }^{23}$. Com os colegas docentes da faculdade sua relação era de respeito, incentivo, generosidade e amizade. Os principais fóruns de debate teológico da faculdade são os que precedem a redação do editorial da revista Perspectiva Teológica, os seminários do corpo docente e os seminários da pós-graduação. Também aí, sua principal atitude era a de levar a sério os temas abordados, através da escuta atenta dos interlocutores, do estudo prévio da temática, da apresentação de sua opinião, do diálogo crítico com os interlocutores. Era leitor de seus colegas docentes, alguns dos quais, como Henrique de Lima Vaz, foram referência em sua vida intelectual e teológica.

Seu quarto interlocutor é constituído por uma variedade de pessoas, instituições e atividades ligadas à pastoral e à assessoria. Uma dessas atividades, pouco conhecida de muitos, é a do acompanhamento espiritual. Libanio foi durante anos orientador espiritual de jovens, de religiosos, de religiosas, de seminaristas, de padres e de bispos. Essa escuta do caminho do Espírito na vida de tantas pessoas plasmou, sem dúvida, sua própria caminhada espiritual, que passou a iluminar também a dos que ele acompanhava. Um dos livros nos quais tematiza esse caminho do Espírito na perspectiva inaciana é $A$ escola da liberdade ${ }^{24}$. Escreveu ainda inúmeros artigos na revista de Itaici na mesma perspectiva, sem contar os da Convergência e Grande Sinal. A prova da importância desta atividade é que sua páscoa definitiva ocorreu num retiro oferecido para professores do Colégio Sion, em Curitiba.

A essa atividade de acompanhamento espiritual precisa ser acrescentada sua pastoral na paróquia N. Sra. de Lourdes, em Vespasiano, MG. Em qual-

\footnotetext{
${ }^{23}$ Dentre as obras publicadas com ex-alunos ou alunos, cf.: LIBANIO, J. B.; BINGEMER, M. C. Escatologia cristã. Petrópolis: Vozes, 1985; LIBANIO, J. B.; MARTINS FILHO, M. A busca do sagrado. São Paulo: FTD, 1991; LIBANIO, J. B.; OLIVEIRA, P. R. F. de. A vida e a morte: desafios e mistérios. São Paulo: Paulinas, 1993; LIBANIO, J. B.; MURAD, A. Introdução à Teologia: perfil, enfoques, tarefas. São Paulo: Loyola, 1996; LIBANIO, J. B.; CUNHA, C. Linguagens sobre Jesus (1): as linguagens tradicional, neotradicional pós-moderna, carismática, espírita e neopentecostal. São Paulo: Paulus, 2011; LIBANIO, J. B.; GUIMARÃES, E. Linguagens sobre Jesus (4): as linguagens das juventudes e da libertação. São Paulo: Paulus, 2013.

${ }^{24}$ LIBANIO, J. B. A escola da liberdade. Subsídios para meditar. São Paulo: Loyola, 2010
} 
quer lugar que se encontrasse no Brasil, Libanio fazia de tudo para chegar na sexta ou no sábado, para celebrar nos domingos. Assegurava nessas missas a pregação ${ }^{25}$, alimentando a iniciação à fé das crianças, na missa dos domingos pela manhã; dos jovens, nas missas noturnas. Há que contar ainda as visitas a doentes, as confissões e os atendimentos.

Esses dois tipos de atividades - acompanhamento espiritual e atividade pastoral - ajudam a entender sua contribuição enquanto assessor em atividades tão importantes como os intereclesiais, as assembleias diocesanas, as semanas teológicas, os encontros de presbíteros, bispos e outros organismos ligados à Igreja católica no Brasil. Sua reflexão e contribuição não eram meramente teóricas. O contato com o "público" igreja, através dessas inúmeras atividades, tornava sua teologia extremamente pastoral, próxima do que acontecia de fato na vida dos fieis e da igreja, de suas pastorais, grupos e atividades de serviço ao povo de Deus.

Por detrás desta atividade variada se encontrava um homem marcado por uma experiência de encontro cotidiano com Deus, por uma vida simples, cordial, próxima, feita de disciplina e alegria, plasmada na escola dos afetos que são os Exercícios Espirituais de Santo Inácio e a espiritualidade da Companhia de Jesus. Apesar da agenda sobrecarregada, sempre encontrava tempo para os amigos. Cultivava-os, mantendo-se fiel aos que a vida e os inúmeros contatos lhe presentearam, abrindo-se a novas relações, com pessoas de todas as procedências e de todos os horizontes sociais, culturais e religiosos. Também é notável sua fidelidade aos companheiros jesuítas, sobretudo aos idosos e aos doentes, através da visita diária que lhes fazia na casa de saúde da Companhia de Jesus próxima das dependências FAJE, e à sua comunidade religiosa, buscando sempre estar presente nas atividades comuns, como reuniões, orações, saídas.

\section{Os eixos temáticos da teologia de Libanio}

Na entrevista de Libanio a Flávio Senra, feita em setembro de 2011, ele dá uma chave de interpretação interessante dos conteúdos teológicos sobre os quais refletiu e escreveu. Segundo ele, sua geração de teólogos teve que "tocar muitos instrumentos"26. Por isso, observa, mais que um eixo temático definido

\footnotetext{
${ }^{25}$ Seus amigos da Paróquia de Vespasiano gravaram durante anos suas homilias, perfazendo 9 volumes.

${ }^{26}$ Anexo 1. Entrevista a Flávio Senra, op. cit., p. 209.
} 
ele elaborou um "eixo-horizonte filosófico-teológico de maneira dialética"27. Ao redor desse eixo ele escreveu sobre os mais diversos assuntos, que por sua vez, levaram à construção lenta de vários eixos temáticos, com escritos e leitura em mútua relação. Essa observação é muito importante, pois retrata bem seu itinerário teológico, os muitos assuntos sobre os quais escreveu. Ela ajuda também a entender o itinerário dos teólogos que lhe foram contemporâneos.

Libanio observa nessa entrevista que desde seus primeiros escritos elaborou suas reflexões no desenvolvimento histórico. No início, a partir de três horizontes: 1) o da objetividade clássica; 2) o das transformações produzidas pelas coordenadas básicas da primeira modernidade (imagem científica do mundo, subjetividade e história); 3) o da especificidade do pensamento latino-americano, com sua ênfase na práxis, em diálogo crítico com a segunda ilustração e a corrente marxista. Nos últimos anos acrescentou um quarto horizonte; o da pós-modernidade, como radicalização da modernidade e como oposição a ela. É a partir desses horizontes que ele explorou vários eixos temáticos, alguns determinados por sua docência e pesquisa, iniciada na PUC Minas e no Cristo Rei, em São Leopoldo, RS, prosseguida na PUC-Rio e continuada, na maior parte do tempo, na FAJE, em Belo Horizonte. Outros oriundos de sua enorme atividade de assessor junto à CRB, à Igreja, às CEBs, à sua atividade pastoral e aos inúmeros interlocutores com os quais estabeleceu uma fecunda relação ao longo de sua vida.

\subsection{Os eixos temáticos provenientes da docência e da pesquisa}

Libanio foi um pesquisador incansável. Não como os grandes eruditos ou especialistas, preocupados em perseguir todos os aspectos de uma determinada área do saber. Como assinalado acima, ele se considerava um "generalista", o que não quer dizer que tenha sido superficial. Levava a sério a pesquisa, como o demonstravam as muitas leituras a que se dedicava todas as manhãs, com disciplina, e que deram origem às centenas de recensões e notas bibliográficas publicadas na Perspectiva Teológica, na Síntese, na REB, na revista Horizonte e em outros periódicos da área da teologia e afins. Parte dessa pesquisa se traduziu nos cursos que deu na graduação, sobretudo na área da teologia fundamental, mas também em outras áreas da sistemática, e na pós-graduação, com temas diversos, como indicado a seguir.

${ }^{27}$ Idem. 
No campo da teologia fundamental escreveu suas obras de maior envergadura e densidade. Serão elencados a seguir os principais livros e capítulos de livros, com a referência completa no próprio texto, para evitar os desvios das notas de rodapé: Fé e existência. In: CINTRA, R. (Coord.). Credo para amanhã 3. Petrópolis: Vozes, 1972, p. 151-167; O eterno problema da fé. Rio de Janeiro: Conferência dos Religiosos do Brasil (CRB), 1974; Teologia da revelação. Rio de Janeiro: PUC Rio, 1977; Fé e política: autonomias específicas e articulações mútuas. São Paulo: Loyola, 1985; Deus e os homens: os seus caminhos. Petrópolis: Vozes, 1990; Teologia da revelação a partir da modernidade. São Paulo: Loyola, 1992 (6 ${ }^{\mathrm{a}}$ ed. 2012); Introdução à Teologia (com Afonso Murad). São Paulo: Loyola, 1996 ( $8^{\text {a }}$ ed. revista e ampliada em 2011); Eu creio, nós cremos: tratado da fé. São Paulo: Loyola, 2000 ( $2^{\mathrm{a}}$. ed. 2005); Itinerário da fé hoje: a propósito da teologia da fé. In: HACKMANN, G. L. B. (Org.). Sub umbris fideliter: Festschrift em homenagem a Frei Boaventura Kloppenburg. Porto Alegre: EDIPUCRS, 1999, p. 185-214 (reeditado em: CNBB. O itinerário da fé na "iniciação cristã de adultos". São Paulo: Paulus, 2001, p. 296-331, em Estudos da CNBB, 82); Crer num mundo de muitas crenças e pouca libertação. Valencia/São Paulo: Paulinas/ Siquem, 2001 ( $2^{\mathrm{a}}$ ed. 2010); Desafios da pós-modernidade à teologia fundamental. In: TRASFERETTI, J.; GONÇALVES, P. S. L. (Org.). Teologia na pós-modernidade. São Paulo: Paulinas, 2003, p. 143-171; Da apologética à teologia fundamental: a revelação cristã. In: GONÇALVES, P. S. G.; BOMBONATTO, V. I. (Org.). Concílio Vaticano II: análise e prospectivas. São Paulo: Paulinas, 2004. p. 165-185; Caminhos de existência. São Paulo: Paulus, 2012; A teologia fundamental: itinerário de um professor. In: MURAD, A.; BOMBONATTO, V. (Org.). Teologia para viver com sentido: homenagem aos 80 anos do teólogo João Batista Libanio. São Paulo: Paulinas, 2012. p. 13-25; Introdução à Teologia Fundamental. São Paulo: Paulus, 2014.

Esse conjunto de obras e textos explora diversos temas da teologia fundamental. Alguns numa perspectiva mais sistemática, refletindo sobre os dois principais conteúdos dessa disciplina teológica, a saber, a revelação e a fé. Outros indicando os desafios do ato de crer no contexto latino-americano, com as mudanças que vão das figuras tradicionais, modernas e pós-modernas. Outros, enfim, exploram questões da epistemologia da inteligência da fé.

No âmbito da teologia sistemática, sua principal obra, por corresponder a uma das disciplinas que ensinou em sua longa carreira docente e por pertencer à coleção Teologia e Libertação, é a que escreveu em coau- 
toria com Maria Clara Bingemer. Escatologia cristã: o novo céu e a nova terra. Petrópolis: Vozes, 1985. Nela Libanio assume a perspectiva de um bom número de teólogos católicos contemporâneos diante da questão da "ressurreição na hora da morte". Além desta obra, uma série de outros textos, alguns de caráter pastoral e catequético, outros mais voltados para um público amplo e elaborados no quadro do grupo de pesquisa Fé e Contemporaneidade, do qual era líder, explora os principais conteúdos da fé, a saber: I) Jesus Cristo: Creio em Jesus Cristo. São Paulo: Paulus, 2007 (2a ed. 2013); Sempre Jesus. A caminho do novo milênio. São Paulo: Paulinas, 1998 (2a ed. 2001); Linguagens sobre Jesus (1): as linguagens tradicional, neotradicional pós-moderna, carismática, espírita e neopentecostal (com Carlos Cunha). São Paulo: Paulus, 2011; Linguagens sobre Jesus (2): linguagens narrativa e exegética moderna. São Paulo: Paulus, 2012; Linguagens sobre Jesus (3): de Cristo carpinteiro a Cristo cósmico. São Paulo: Paulus, 2013; Linguagens sobre Jesus (4). As linguagens das juventudes e da libertação (com Edward Guimarães). São Paulo: Paulus, 2013; II) Deus: Creio em Deus Pai. São Paulo: Paulus, 2007 (2 $2^{\mathrm{a}}$ ed. 2012); Creio no Espírito Santo. São Paulo: Paulus, 2007 (2 ${ }^{\mathrm{a}}$ ed. 2008); III) o ser humano: Pecado e opção fundamental. Petrópolis: Vozes, 1975; Deus e os homens: os seus caminhos. Petrópolis: Vozes, 1990.

A quantidade maior de textos dedicados a Jesus é fruto de um novo interesse que essa temática despertou no teólogo mineiro, sobretudo nos últimos anos, com as novas perspectivas dos estudos sobre o Jesus histórico. Esse conjunto de textos, com exceção de sua obra sobre a escatologia, não tinha a pretensão de ser uma palavra de especialista, mas a de um teólogo atento às discussões presentes nesses âmbitos da teologia sistemática, preocupado em divulgar numa linguagem mais acessível a um público maior o conteúdo central da fé cristã.

2.2. Os eixos temáticos oriundos de sua presença na vida da Igreja e na teologia

Libanio participou ativamente dos debates teóricos sobre a teologia latino-americana, dando também uma contribuição própria, não só em nível de divulgação. Além disso, foi responsável, junto com outros teólogos de sua geração, por um trabalho de divulgação e de reflexão sobre o Concílio, sobre a vida religiosa, a nova maneira de ser Igreja das comunidades eclesiais de base e das pastorais, a evangelização dos jovens.

Uma de suas contribuições mais significativas para a teologia latino-americana foi, sem dúvida, a obra Teologia da libertação: roteiro didático para 
um estudo. São Paulo: Loyola, 1987, pois nela realiza uma primeira sistematização do pensamento teológico do continente. Anos depois, junto com Alberto Antoniazzi, escreveu: Vinte anos de teologia na América Latina e no Brasil. Petrópolis: Vozes, 1994. Escreveu ainda artigos, verbetes para dicionários e enciclopédias, capítulos de livros e artigos em vários periódicos, onde retoma e aprofunda o específico desta corrente teológica pós-conciliar. Dentre esses textos se destacam: Libertação. In: RODRIGUEZ, A.A.; CANALS CASAS, J. (Dir.). Dicionário teológico da vida consagrada. São Paulo: Paulus, 1994. p. 597-608; Doutrina social da Igreja e teologia da libertação. In: IVERN, F.; BINGEMER, M. C. L. (Org.). Doutrina social da Igreja e teologia da libertação. São Paulo: Loyola, 1994, p. 43-67; Perspectivas e desafios futuros da teologia da libertação. In: ROCHA, Z. (Org.). Helder, o Dom: uma vida que marcou os rumos da Igreja no Brasil. Petrópolis: Vozes, 1999, p. 137-147; Religião e teologia da libertação. In: SUSIN, L. C. (Org.). Sarça ardente: teologia na América Latina: prospectivas. São Paulo: Paulinas, 2000. p. 79-144; A teologia da libertação. In: ALMEIDA, E. F.; LONGUINI NETO, L. (Org.). Teologia para quê? Rio de Janeiro: Mauad X: Instituto Mysterium, 2007, p. 33-52; Evangelização e libertação: o itinerário de um teólogo. In: BARROS, P. C. (Org.). A serviço do evangelho: estudos em homenagem a J. A. Ruiz de Gopegui, SJ, em seu $80^{\circ}$ aniversário. São Paulo: Loyola, 2008. p. 23-41; Teologia da libertação: pontos consolidados, críticas e perspectivas. In: MURAD, A.; BOMBONATTO, V. (Org.). Teologia para viver com sentido: homenagem aos 80 anos do teólogo João Batista Libanio. São Paulo: Paulinas, 2012, p. 151-158.

Um conjunto representativo de obras, aqui reagrupado ao redor do eixo Igreja em contexto, explora temas como religião, Igreja, Concílio Vaticano II e cristianismo na atualidade: $A$ volta à grande disciplina: reflexão teológico-pastoral sobre a atual conjuntura da Igreja. São Paulo: Loyola, $1983\left(2^{\mathrm{a}}\right.$ ed. 1984); Cenários da Igreja. São Paulo: Loyola, 1999 (2ª ed. 2000); Igreja contemporânea: encontro com a modernidade. São Paulo: Loyola, 2000; A Religião no início do milênio. São Paulo: Loyola, 2002; Olhando para o futuro: prospectivas teológicas e pastorais do cristianismo na América Latina. São Paulo: Loyola, 2003; Concílio Vaticano II. Em busca de uma primeira compreensão. São Paulo: Loyola, 2005; Os carismas na Igreja do Terceiro Milênio. Discernimento, desafios e práxis. São Paulo: Loyola, 2007; Qual o futuro do Cristianismo? São Paulo: Paulus, 2006; Em busca de lucidez. O fiel da balança. São Paulo: Loyola, 2008; Conferências gerais do Episcopado Latino-Americano: do Rio de Janeiro a Aparecida. São Paulo: Paulus, 2007. 
Além dessas obras haveria que acrescentar os artigos que publicou em revistas especializadas sobre os mesmos temas, mas também os textos sobre as comunidades eclesiais de base e as pastorais da igreja latino-americana, grande parte deles publicada na REB e na Vida Pastoral. Essas obras mostram como Libanio percebia os "sinais dos tempos" da realidade mutante da América Latina e os desafios que representavam para a Igreja católica, o cristianismo e as religiões nessa região.

O teólogo jesuíta trabalhou ainda temas diversos da pastoral, da vida religiosa e da espiritualidade nos livros: A evangelização no mundo contemporâneo: Evangelii Nuntiandi. São Paulo: Loyola, 1976; O mundo dos jovens: reflexões teológico-pastorais sobre os movimentos de juventude da Igreja. São Paulo: Loyola, 1978 (2a ed. 1983); As grandes rupturas socioculturais e eclesiais: sua incidência sobre a vida religiosa. Petrópolis: Vozes, 1980 ( $2^{\mathrm{a}}$ ed. 1981); O que é pastoral. São Paulo: Brasiliense, 1982 (2 ed. 1983); Pastoral numa sociedade de conflitos. Petrópolis/ Rio de Janeiro: Vozes/CRB, 1982; Fé e política: autonomias específicas e articulações mútuas. São Paulo: Loyola, 1985; As lógicas da cidade: o impacto sobre a fé e sob o impacto da fé. São Paulo: Loyola, 2001 (2 ed. 2002); Jovens em tempo de pós-modernidade. Considerações socioculturais e pastorais. São Paulo: Loyola, 2004; Juventude: seu tempo é agora. São Paulo: Ave Maria, 2008. Em todas essas obras há que destacar a preocupação de Libanio com o anúncio do Evangelho.

A esses trabalhos ainda é necessário acrescentar outros, especificamente voltados para a vida religiosa, a espiritualidade e a educação: A consciência crítica do religioso. Rio de Janeiro: CRB, 1974; Vida religiosa e testemunho público. Rio de Janeiro: CRB, 1971; A vida religiosa na crise da modernidade brasileira. São Paulo: Loyola, 1995; Vida religiosa: sempre a renascer. São Paulo: Paulinas, 1995; Obediência na liberdade. São Paulo: Paulinas, 1995; Discernimento espiritual: reflexões teológico-espirituais. São Paulo: Loyola, 1977; Discernimento e politica. Petrópolis: Vozes, 1977; O discernimento espiritual revisitado. São Paulo: Loyola, 2000; Missão e serviço na vida religiosa. São Paulo: Centro de Documentação e Comunicação dos Marginalizados, 1991; Evangelização e libertação: reflexões aplicadas à vida religiosa. Petrópolis: Vozes, 1975 (2a ed. 1976); A escola da liberdade. São Paulo: Loyola, 2010; Educação para uma sociedade justa. São Paulo: Loyola, 1981; Educação católica: atuais tendências. São Paulo: Loyola, 1983.

Finalmente, há que assinalar textos produzidos ao longo da vida de Libanio dedicados ao ensino da arte de pensar e escrever: Formação da cons- 
ciência crítica: subsídios filosófico-culturais (1). Petrópolis: Vozes, 1978 (2a ed. 1980); Formação da consciência crítica: subsídios sócio-analíticos (2). Petrópolis: Vozes, 1979 (2 ${ }^{\mathrm{a}}$ ed. 1980); Formação da consciência crítica: subsídios psicopedagógicos (3) (com Luiz Augusto Monnerat). Petrópolis: Vozes, 1979; Ideologia e cidadania. São Paulo: Moderna, 1995 (2 ${ }^{\mathrm{a}}$ ed. 2004); A arte de formar-se. São Paulo: Loyola, 2001 ( 6 a ed. 2012, revista e ampliada); Introdução à vida intelectual. São Paulo: Loyola, 2001 (4ª ed. 2012).

Muitas dessas obras foram traduzidas em diversas línguas, sobretudo para o espanhol. A elas há que acrescentar centenas de artigos científicos publicados nas principais revistas especializadas em teologia, espiritualidade, pastoral e vida religiosa no Brasil e no exterior, como também verbetes publicados em dicionários e enciclopédias. Durante anos Libanio colaborou em colunas de jornais e portais de grande divulgação, como O tempo, Jornal de Opinião, Portal Dom Total, apresentando seu olhar crítico de teólogo sobre a realidade do cotidiano. Como foi indicado acima, seus amigos da Paróquia de N. Sra. de Lourdes, em Vespasiano, MG, onde trabalhou por quase trinta anos como vigário paroquial, gravaram e publicaram em nove tomos suas homilias, que são fonte de inspiração para a vida e a pregação.

\section{Conclusão}

Provavelmente Libanio é um dos teólogos brasileiros que mais escreveu nos últimos 50 anos. Iluminou sob muitos pontos de vista a vida da Igreja, com sua análise crítica, lúcida e corajosa dos diferentes deslocamentos que a sociedade e a igreja católica brasileira e latino-americana conheceram nesse mesmo período. Não só a Igreja, com suas pastorais, sua presença na sociedade, seu testemunho através da vida religiosa, foi beneficiada por sua atividade de escritor, conferencista, assessor, pregador e acompanhante. Também outros "públicos", muitos deles mais acadêmicos, de várias áreas do saber, puderam beber de sua sabedoria, de seu amplo conhecimento, produzido por uma mente inquieta, nunca satisfeita e acomodada, mas sempre curiosa e em busca se atualizar e comunicar a outros o que de novo descobria, intuía e produzia. Enfim, muitos homens e mulheres, independentemente de estar nas comunidades, nas pastorais, na vida religiosa ou na academia, puderam receber desse irmão em humanidade, à luz de sua fé em Jesus Cristo, palavras de ânimo, solidariedade e lucidez crítica, que as ajudaram a se situar melhor na sociedade, a dar sentido às suas existências, a assumir compromissos com 
a transformação desse mundo em uma sociedade de irmãos e irmãs, primícias do reino anunciado pelo Nazareno e testemunhado de tantas formas por seus discípulos e discípulas ao longo da história. Oxalá seu exemplo e sua figura continuem iluminando a Igreja e todos aqueles que o tiveram como amigo, mestre, irmão e companheiro de caminhada. Oxalá também novas vocações, com o mesmo ardor, ânimo, generosidade, seriedade e ousadia, surjam no contexto no qual ele atuou, para continuar discernindo os sinais dos tempos e apontando como acolhê-los.

\section{Referências Bibliográficas}

DE MORI, G. Anexo II. Ouvinte e servidor da Palavra: Bibliografia primária de João Batista Libanio. In Teologia para viver com sentido, p. 211-238.

DE MORI, G.; OLIVEIRA, P. R. João Batista Libanio, SJ. In PANASIEWICZ, R.; VITÓRIO, J. Espiritualidades e dinâmicas sociais. Memória Prospectivas. São Paulo: Paulinas, 2014, p. 186-200.

LIBANIO, J. B. Itinerário intelectual. Conferência apresentada em 2006 à comissão de teólogos da Conferência de Provinciais da América Latina - CPAL (pro manuscrito).

LIBANIO, J. B. 70 anos de um teólogo. Entrevista de João Batista Libanio. Jornal de Opinião, Junho de 2002.

LIBANIO, J. B. Formação da consciência crítica: subsídios filosóficoculturais. Petrópolis: Vozes, 1978. v. 1;

LIBANIO, J. B. Formação da consciência crítica: subsídios sócio-analíticos. Petrópolis: Vozes, 1979. v. 2;

LIBANIO, J. B. Formação da consciência crítica: subsídios psicopedagógicos. Petrópolis: Vozes, 1979. v. 3.

LIBANIO, J. B. Cenários da Igreja: num mundo plural e fragmentado. São Paulo: Loyola, 1999.

LIBANIO, J. B. A escola da liberdade. Subsídios para meditar. São Paulo: Loyola, 2010.

LIBANIO, J. B. Linguagens sobre Jesus (2): as linguagens narrativa e exegética moderna. São Paulo: Paulus, 2012. 
LIBANIO, J. B. Linguagens sobre Jesus (3): as linguagens narrativa e exegética moderna. São Paulo: Paulus, 2012.

LIBANIO, J. B.; CUNHA, C. Linguagens sobre Jesus (1): as linguagens tradicional, neotradicional pós-moderna, carismática, espírita e neopentecostal. São Paulo: Paulus, 2011.

LIBANIO, J. B.; GUIMARÃES, E. Linguagens sobre Jesus (4): as linguagens das juventudes e da libertação. São Paulo: Paulus, 2013.

LIBANIO, J. B.; BINGEMER, M. C. Escatologia cristã. Petrópolis: Vozes, 1985.

LIBANIO, J. B.; MARTINS FILHO, M. A busca do sagrado. São Paulo: FTD, 1991.

LIBANIO, J. B.; OLIVEIRA, P. R. F. de. A vida e a morte: desafios e mistérios. São Paulo: Paulinas, 1993.

LIBANIO, J. B.; MURAD, A. Introdução à Teologia: perfil, enfoques, tarefas. São Paulo: Loyola, 1996.

MURAD, A.; BOMBONATO, V. Teologia para viver com sentido. São Paulo: Paulinas, 2012.

SENRA, F. Anexo I. Entrevista a Flávio Senra. In Teologia para viver com sentido, p. 197-210.

TRACY, D. A imaginação analógica. A teologia cristã e a cultura do pluralismo. São Leopoldo: Unisinos, 2006.

Geraldo Luiz De Mori, SJ

Doutor em Teologia Professor de antropologia teológica e escatologia cristã na FAJE Belo Horizonte / MG - Brasil E-mail: geraldodemori@faculdadejesuita.edu.br

Recebido em: 24/10/14

Aprovado em: 05/11/14 